ra chưa thích nghi được cách học tập ở trường đại học cũng là yếu tố nguy cơ làm tăng stress gấp 2,411 sinh viên đã thích nghi được việc học ở đại học

\section{KẾT LUÂ̂N}

Tỷ lệ sinh viên năm thứ nhất hệ bác sĩ $Y$ khoa gặp stress là $42,6 \%$. Trong đó mức độ nặng và rẩt năg chiếm tỷ lệ $8,4 \%$ và $3,2 \%$. Các yếu tố liên quan có thể kể đến các yếu tố: xung đột với bạn cùng phòng, kết thúc một tình bạn, rắc rối với bố mẹ, sức khỏe giảm sút, thay đổi hành vi trong việc sử dụng rượu bia, thuốc lá hoặc chất gây nghiện, gia tăng việc học ở trường quá nhiề, điểm học không như mong đợi, chưa thích nghi được với cách học ở trường đại học

\section{TÀI LIÊU THAM KHẢO}

1. Selye H. Forty years of stress research: principal remaining problems and misconceptions. Can Med Assoc J. 1976;115(1):53-56.
2. Abdulghani HM, AlKanhal AA, Mahmoud ES, Ponnamperuma GG, Alfaris EA. Stress and Its Effects on Medical Students: A Cross-sectional Study at a College of Medicine in Saudi Arabia. J Health Popul Nutr. 2011;29(5):516-522.

3. Lê Hoàng Thành Nhung. Stress và các yếu tố liên quan ở sinh viên khoa Y tế công cộng Đại học Y dước thành phố Hồ Chính Minh. Tap chí Ý học thực hành. Số 1 . Năm 2018

4. Phạm Thị Huyên Trang. Thực trạng stress trong sinh viên trường Đại học Y hà Nội 2013.

5. Nguyển Hoàng Nguyền. Trầm cảm, lo âu và stress ở sinh viên hệ bác sĩ trường Đại học Y Hà Nội năm học 2018-2019 và một số yếu tố liên quan.

6. Triệu Thi Đào, 2016 thực trang và các yếu tố liên quan đến stress của sinh viên năm thứ ba trường đại học y hà nội.

7. Trân Thị Thanh Hương, Vũ Dũng. Thực trạng của sinh viên điêu dưỡng năm 2,3 của trường Đ̇ại học Thăng Long, năm 2015 và một số yếu tố liên quan. Tap chí Y học Việt Nam. số chuyên đề. năm 2017

8. Đăng Đức Nhu. Thức trang và các yếu tố liên quan đến stress của sinh viên năm thứ ba trường Đaai học Công nghệ đại học quốc gia Hà Nội năm 2015. Tạp chí Y học Dự phòng. số 1. Năm 2016.

\title{
ĐÁNH GIÁ KẾT QUẢ NộI SOI NGƯợC DÒNG TÁN SỎI NIỆU QUẢN 1/3 DƯớI TẠI BỆNH VIỆN HỮU NGHI VIỆT ĐỨC
}

\section{TÓM TẮT.}

Mục tiêu: đánh giá kết quả điều trị, những yếu tố ảnh hưởng đến kết quả điều trị và tỷ lệ tai biến, biến chứng của phương pháp nội soi ngược dòng tán sỏi niệu quản $1 / 3$ dưới. Đối tượng và hương pháp: Mô tả tiến cứu trên 81trường hợp có sỏi niệu quản 1/3 dưới được nội soi tán sỏi ngược dòng bằng laser Holmium tại khoa Phẫu thuật tiết niệu, Bệnh viện Hữu nghị Việt Đức từ tháng 6/2020 - 6/2021. Kết quả: 81 BN gồm 49 nam $(60,5 \%)$ và 32 nữ $(39,5 \%)$. Tuổi trung bình 47,9 $\pm 14,4$ tuổi (22-78). Sói NQ phải $43,2 \%$, sỏi NQ trái $56,8 \%$. Mức độ ứ nước thận trước mổ: 4 đài bể thận bình thường $(4,9 \%) ; 59$ độ I $(72,8 \%) ; 11$ độ II $(13,6 \%) ; 7$ độ III $(8,6 \%)$. Kích thước sởi trung bình: $9,72 \pm 3,76 \mathrm{~mm}(3-25 \mathrm{~mm})$. Thời gian phẫu thuâtt trung bình: $31,7 \pm 12,5$ phút $(10-65$ phút). Kết quả khi ra viện: Thành công $98,8 \%$, trong đó $88,9 \%$ đạt kết quả tổt, thất bại 1 ca $(1,2 \%)$ do sói chạy lên thận. Thời gian nằm viện trung bình: $4,06 \pm 1,93$ ngày (3-14 ngày). Theo dõi sau mổ 1tháng: mức độ giãn đài bể thận được cải thiện và tỷ lệ sạch sỏi đạt $100 \%$. Kích thước sỏi, tình trạng niệu

\footnotetext{
*Trường Đại học Y Hà Nội

**Bênh viển Việt Đức

Chịu trách nhiệm chính: Nguyễn Thế Thịnh

Email: ntthinhqn@gmail.com

Ngày nhận bài: 11.8.2021

Ngày phản biên khoa học: 6.10.2021

Ngày duyệt bài: 14.10 .2021
}

\section{Nguyễn Thế Thịnh*, Đỗ Trường Thành**}

quản và mức độ ứ nước thận ảnh hưởng đến kết quả tán sỏi. Tuổi, giới, số lượng sỏi không ảnh hưởng đến kết quả tán sỏi. Kết luận: Tán sỏi niệu quản ngược dòng bằng Laser Holmium là phương pháp an toàn, hiệu quả trong điều trị sỏi niệu quản $1 / 3$ dưới.

Tư khóa: sỏi niệu quản 1/3 dưới, tán sỏi nội soi ngược dòng, holmium laser.

\section{SUMMARY \\ EVALUATE RESULT'S URETEROSCOPY \\ LITHOTRIPSY BY HOLMIUM LASER AT VIETDUC UNIVERSITY HOSPITAL}

Objectives: to evaluate the treatment results, the factors affecting the outcome and the rate of complications of the Holmium YAG URL. Subjects and methods: Prospective study on 81 cases of lower third ureteral lithiasis treated with ureteroscopy with Holmium laser lithotripsy in Department of Urology, Viet Duc university Hospital between 6/20206/2021. Results: 49 males $(60,5 \%)$ and 32 females $(39,5 \%)$ with the everage age of $47,9 \pm 14,4$ (range from 22 to 78 years old). Right ureteral stones: $43,2 \%$; Left ureteral stones: $56,8 \%$. Estimate thehydronephrosison preoperative includes: 4 normal $(4,9 \%) ; 59$ grade I $(72,8 \%) ; 11$ grade II $(13,6 \%)$ and 7 grade III $(8,6 \%)$. Mean size stone: $9,72 \pm 3,76 \mathrm{~mm}$ (from 3 to 25 millimeters). Average operative time: $31,7 \pm 12,5$ minutes (from 10 to 65 minutes). Success rate at dischage: $98,8 \%$, in which $88,9 \%$ had good result. One failed case $(1,2 \%)$ due to the migration of the stone to the kidney. At 1 month follow up, the 
degree of calyceal dilation was resolved, stone clearance rate was $100 \%$. The mean of hospital stay: 4,06 $\pm 1,93$ ngày (3 - 14 ngày). Stone size, ureteral state and hydronephrosis are factors that affect the result while gender, age and number of stone do not. Conclutions: Ureteroscopy with Holmium laser lithotripsy is safe, effective treatments for removal of distal ureteral calculi.

Key words: lower third ureteral lithiasis, ureteroscopy, holmium laser, lithotripsy

\section{I. ĐĂT VẤN ĐỀ}

Sỏi niệu quản là một trong những bệnh lý thường gặp nhất ở khoa cấp cứu, tỷ lệ hiện mắc suốt đời ước tính khoảng $10 \%$ đến $15 \%{ }^{1}$. Bệnh nhân bị sỏi niệu quản thường có thể xuất hiện đau quặn thận dữ dội do sỏi tắc nghẽn đột ngột niệu quản. Điều trị sỏi niệu quản có thể thay đổi từ việc điều trị nội khoa đến các thủ thuật xâm lấn tối thiểu như tán sỏi bằng sóng xung kích ngoài cơ thể (ESWL), tán sỏi nội soi ngược dòng (URS) và mổ nội soi hoặc mổmở. Hiện nay, tán sỏi nội soingược dòng đã trở thành lựa chọn hàng đầu trong việc điều trị sỏi niệu quản đoạn giữa và dưới do tính an toàn và hiệu quảe ${ }^{2}$ Ưu điểm chính của laser holmium là nó có thể đánh tan một cách hiệu quả các viên sỏi bất kể kích thước, độ cứng, thành phần hóa học, hoặc tính chất vật lý của chúng; do đó có thể đạt được tỷ lê sạch sỏi $\mathrm{cao}^{3}$. Do đó, nó được khuyến cáo là tiêu chuẩn vàng cho tán sỏi nội soi để điều trị sỏi đường tiết niệu ${ }^{4}$. Mặc dù tính an toàn và hiệu quả của nó đã dần được cải thiện, nó vẫn có một tỷ lệ thất bại phẫu thuật nhất định ${ }^{5}$. Chúng tồi tiến hành thực hiện nghiên cứu nhằm đánh giá kết quả điều trị, những yếu tố ảnh hưởng đến kết quả điều trị và tỷ lệ tai biến, biến chứng của phương pháp nội soi ngược dòng tán sỏi niệu quản $1 / 3$ dưới tại Bệnh viện hữu nghị Việt Đức giai đoạn 2020 - 2021.

\section{II. ĐỐI TƯỢNG VÀ PHƯƠNG PHÁP NGHIÊN CỨU}

2.1. Đối tượng nghiên cứu: Gồm 81 bệnh nhân có sỏi niệu quản $1 / 3$ dưới được nội soi tán sỏi ngược dòng bằng laser Holmium tại khoa Phẫu thuật tiết niệu, Bệnh viện Hữu nghị Việt Đức từ tháng 6/2020 - 6/2021.

\section{Tiêu chuẩn lựa chọn bệnh nhân:}

+ Sỏi niệu quản có đường kính lớn nhất $\geq$ $5 \mathrm{~mm}$ hoặc sỏi niệu quản có đường kính lớn nhất $<5 \mathrm{~mm}$ nhưng điều trị nội khoa thất bại sau 1 tháng.

+ Vị trí sỏi: sỏi ở vị trí đoạn $1 / 3$ dưới của niệu quản.

+ Không có nhiễm khuẩn tiết niệu hoặc nhiễm khuẩn tiết niệu đã điều trị ổn định.

2.2 Thiết kế nghiên cứu: Nghiên cứu mô tả tiến cứu, thời gian: từ 1/6/2020 đến hết 30/6/2021.

2.3. Chỉ tiêu nghiên cứu:

*Kích thước sỏi: Kích thước dọc lớn nhất ghi nhận được trên siêu âm và CLVT, tính bằng $\mathrm{mm}$.

*Thời gian tán sỏi: Tính từ khi bắt đâu đặt máy đến khi kết thúc đặt ống thông niệu quản.

*Đánh giá kết quả điêu trị khi xuất viện:Chúng tôi đánh giá kết quả TSNS là thành công hay thất bại theo cách phân loại của Vũ Lê Chuyên (2006)

- Thành công: Sỏi tán hết thành những mảnh $<3 \mathrm{~mm}$. Nhóm thành công chia ra ba mức độ:

+Kết quả tốt: Tán và lấy hết các mảnh sỏi, không có tai biến, biên chứng.

+Kết quả trung bình: Tán và lấy hết sỏi, nhưng có tai biến mức độ nhẹ (xước niêm mạc niệu quản, lỗ niệu quản, cháy máu nhẹ).

+ Kết quả kém: Tán hết sỏi, nhưng lấy không hết hoặc có tai biến, tuy nhiên không phải phối hơp phương pháp khác điều trị và khắc phục được bằng xông niệu quản hoăc ống xông JJ.

- Thất bại: không tán hết được sỏi, phải chuyển phương pháp khác để điều trị do nhiều nguyên nhân: Không đặt được ống soi vào niệu quản và không tiếp cận được sỏi; sỏi cứng quá không tán được phải mổ; biến chứng xảy ra trong tán phải mổ.

* Đánh giá kêt quả tái khám lại sau 1 tháng:

- Chụp XQuang hệ tiết niệu không chuẩn bị: Đánh giá tỷ lệ sạch sỏi và tình trạng sonde JJ.

- Siêu âm hể tiết niệu đánh giá tình trạng sỏi tồn dư (nếu có), mức độ giãn của thận.

+ Nếu sạch sỏi hoàn toàn rút xông JJ cho bệnh nhân tại phòng khám và cho ra viện ngay trong ngày.

+ Nếu còn mảnh sỏi nhỏ $>5 \mathrm{~mm}$ bệnh nhân được tán sỏi ngoài cơ thể.

+ Nếu còn mảnh sỏi nhỏ < $5 \mathrm{~mm}$ bệnh nhân được điều trị nội khoa và khám lại.

- Đánh giá kết quả điều trị sau 1 tháng:

+ Tốt: Sạch sỏi, không còn sỏi, rút được xông JJ, mức độ giãn thận cải thiện

+ Trung bình: Sạch sỏi, mức độ giãn thận không cải thiện, chưa rút được xông jJ.

+ Kém: Không sạch sỏi.

\section{KẾT QUẢ NGHIÊN CỨU}

81 BN gồm 49 nam chiếm $60,5 \%$ và 32 nữ chiếm $29,5 \%$. Tuổi trung bình là $47,9 \pm 14,4$ tuổi (22 -78). Độ tuổi nhiều nhất $20-60$ tuổi gặp 61 $\mathrm{BN}$ chiếm $75,3 \%$. 2/81 trường hợp (2,5\%) sỏi trên BN mang thai (17-22 tuân); 2/81 trường hợp $(2,5 \%)$ sỏi niệu quản sau TSNCT, $2 / 81$ trường hợp $(2,5 \%)$ sỏi niệu quản 2 bên, $1 / 81$ trường hợp 
$(1,2 \%)$ sỏi niệu quản trên thận duy nhất.

Ứ nước độ I gặp nhiều nhất (59/81 BN, chiếm $72,8 \%)$ và ĐBT không giãn gặp ở 4/81 BN (4,9\%). Ứ nước độ II gặp ở $11 / 81 \mathrm{BN}$, chiếm $13,6 \%$ và ứ nước độ III gặp ở 7/81 BN, chiếm 8,6\%.

Có tổng số 95 viên sỏi/ 81 BN, trong đó có $69 / 81$ BN $(85,2 \%)$ có duy nhất 1 viên sỏi niệu quản $1 / 3$ dưới, $12 / 81 \mathrm{BN}(14,8 \%)$ có từ 2 viên sỏi trở lên trên cùng đoạn niệu quản $1 / 3$ dưới. Kích thước sỏi trung bình: $9,72 \pm 3,76 \mathrm{~mm}(3-25 \mathrm{~mm})$.

Xét nghiệm: $20 / 81 \mathrm{BN}(24,7 \%)$ có nồng độ Creatinin máu $>120 \mu \mathrm{mol} / \mathrm{l}$.

Chẩn đoán hình ảnh: $X Q$ hệ tiết niệu không chuẩn bị phát hiện được 44/79 BN $(55,7 \%)$ có sỏi, siêu âm hệ tiết niệu phát hiện được 62/81 BN $(76,5 \%)$ có sỏi, phối hợp cả 2 phương pháp phát hiện được $71 / 81$ BN $(87,7 \%)$ có sỏi. CLVT phát hiện được 79/79 BN (100\%) có sỏi. Có 2/81 BN $(2,5 \%)$ có thai không được chụp $X Q$ hay CLVT nhưng đều phát hiện được sỏi niệu quản 1/3 dưới trên siêu âm.

*Quá trình tán sỏi: $21 / 81 \mathrm{BN}(25,9 \%)$ có lỗ niệu quản phù nề. $30 / 81 \mathrm{BN}(37,0 \%)$ phù nề niểm mạc niệu quản tại vị trí sỏi. $6 / 81$ BN $(7,4 \%)$ hẹp niệu quản đoạn dưới sỏi.

Tất cả các trường hợp đều tiếp cận thành công sỏi (100\%).

Thời gian phẫu thuật trung bình: $31,7 \pm 12,5$ phút (10- 65 phút).

$1 / 81$ trường hợp $(1,2 \%)$ có mảnh sỏi $>3 \mathrm{~mm}$ chạy lên đài thận không thể tiếp tục tán. 8/81 trường hợp $(9,9 \%)$ tổn thương niêm mạc niệu quản gây chảy máu mức độ vừa, không thay đổi huyết động, không ảnh phải dừng tán sỏi và diễn biến sau mổ ổn định, không phải truyền máu. Sau khi tán và lấy sỏi, tất cả các bệnh nhân đều được đặt ống thông J] cõ 6 -7Fr, chiếm 100\%.Tỷ lệ sạch sỏi trong mổ đạt 98,8\%.

*Diến biến sau mổ: 45/81 BN (55,6\%) BN diễn biến ổn định sau mổ, không có triệu chứng gì đặc biệt. $27 / 81 \mathrm{BN}(33,3 \%)$ có đái máu sau mổ, mức độ đái máu nhẹ, không ảnh hưởng đến huyết động và không cần phải truyền máu, triệu chứng thường tự hết sau 1-2 ngày. 8/81 BN $(9,9 \%)$ đau âm ì thắt lưng bên tán sỏi, tự hết sau 2-3 ngày và đều đáp ứng với thuốc giảm đau thông thường. 1/81 BN $(1,2 \%)$ sốt nhẹ điều trị ổn định ra viện được phân loại Clavien Dindo độ I.

Rút thông niệu đạo sau 2-3 ngày. Thời gian nằm viện trung bình: 4,06 $\pm 1,93$ ngày ( 3 - 14 ngày).

Kết quả tán sỏi khi ra viện: 80/81 BN $(99,8 \%)$ thành công, trong đó có $88,9 \%$ đạt kết quả tốt, $1 / 81 \mathrm{BN}$ thất bại $(1,2 \%)$ do mảnh sỏi $>3 \mathrm{~mm}$ chạy lên đài thận không thể tiếp tục tán, sau mổ điều trị nội khoa chưa can thiệp thêm. Nghiên cứu cho thây kích thước sỏi không liên quan một cách có ý nghĩa thống kê đến kết quả tán sỏi $(p=0,038)$. Tình trạng niệu quản và mức độ ứ nước thận liên quan một cách có ý nghĩa đến kết quả tán sỏi $(\mathrm{p}=0,001)$.

Bảng 3.1: Các yêu tố không liên quan đến kêt quả (hồi quy logistic đa biến) (p>0,05)

\begin{tabular}{|c|c|c|c|c|c|}
\hline & B & Std. Error & Beta & t & Sig. \\
\hline Tuối &, 052 &, 097 &, 061 &, 531 &, 0597 \\
\hline Giới &,- 075 &, 090 &,- 098 &,- 830 &, 409 \\
\hline Độ cản quang &, 082 &, 086 &, 110 &, 953 &, 344 \\
\hline Vị trí bên có sỏi &, 047 &, 090 &, 063 &, 518 &, 606 \\
\hline Số lượng sỏi &,- 130 &, 0121 &, 126 & 1,070 &, 288 \\
\hline
\end{tabular}

Các yếu tố như tuổi, giới tính, vị trí bên có sỏi, số lượng sỏi, độ cản quang không ảnh hưởng đến kết quả điều trị $(p>0,05)$

*Theo dõi sau mổ 1 tháng: $77 / 81 \mathrm{BN}$ $(95,1 \%)$ quay lại khám đúng hẹn sau 4 tuần. Tất cả các bệnh nhân đều được siều âm hệ tiết niệu (100\%), 75/77 BN (97,4\%) được chụp XQ hệ tiết niệu. Tất cả các bệnh nhân đều sạch sỏi (100\%), mức độ ứ nước thận được cải thiện: 85,7\% BN không có ứ nước thận, $11,7 \%$ ứ nước thận độ $\mathrm{I}$, 2,6\% BN ứ nước thận độ II. Không có BN nào ứ nước thận độ III và IV. Không gặp biến chứng đái máu hay nhiễm khuẩn tiết niệu. Tất cả các BN đều được rút JJ tại phòng thủ thuật tiết niệu và ra về trong ngày.

\section{BÀN LUÂN}

Theo Hiệp hội tiết niệu châu Âu (EAU), đối với sỏi niệu quản $1 / 3$ dưới có kích thước $<10 \mathrm{~mm}$ thì có thể sử dụng TSNS ngược dòng hoặc TSNCT, tuy nhiên với những viên sỏi có kích thước > $10 \mathrm{~mm}$ thì ưu tiên số 1 là TSNS ngược dòng. Trong nghiên cứu của chúng tôi, đa số bệnh nhân có sỏi kích thước $<10 \mathrm{~mm}(80,24 \%)$, điêu này cho thấy vai trò xu hướng sử dụng TSNS niệu quản ngày càng phổ biến hơn.

Trong tán sỏi niệu quản nội soi giai đoạn tiếp cận sỏilà quan trọng nhất. Nguyên nhân cản trở thường gặp nhất trong việc tiếp cận sỏi là do các tổn thương của lố niệu quản và dị dạng niệu quản. Trong nghiên cứu của chúng tôi có 6 trường hợp hẹp niệu quản do viêm dính tại vị trí 
sỏi cần thực hiện thủ thuật nong niệu quản hoặc đốt xơ hẹp (7,4\%), không có trường hợp nào có polyp niệu quản cần can thiệp. Trong nghiên cứu này, chúng tôi ghi nhận $100 \%$ bệnh nhân đều tiếp cận sỏi thành công.Khi tán sỏi cần lưu ý là tránh làm tổn thương niệu quản cũng như làm sỏi di chuyển lên thận. Chúng tôi ghi nhận có 1 trường hợp mảnh sỏi chạy lên thận khổng thể tiếp tục tán $(1,2 \%)$ và 8 trường hợp tổn thương niêm mạc niệu quản $(9,9 \%)$,không có trường hợp nào thủng hay đứt niệu quản. Nghiên cứu của chúng tôi có thời gian mổ trung bình $32,6 \pm$ 14,0 phút ( 10 - 65 phút), đa số các trường hợp có thời gian tán sỏi trong khoảng $20-<40$ phút $(58,0 \%)$.Thời gian tán sỏi phụ thuộc vào nhiều yếu tố như kinh nghiệm của phẫu thuật viên, loại sỏi to, cứng, tình trạng của niệu quản như phù nề, hẹp, polyp phải phối hợp các thủ thuật như nong niệu quản, đốt xơ hẹp, đốt polyp...

Tất cả các bênh nhân đều được đă̆t sonde JJ để giúp niêm mạc niệu quản liền tốt, tránh gây dính, hẹp niệu quản và tránh tình trạng tắc niệu quản do cục máu đông hay sót sỏi sau mổ. Tất cả các trường hợp đều được rút sonde JJ tại phòng thủ thuật sau 4 tuần khi tái khám.

Sau mổ chúng tôi không gặp các biến chứng như chảy máu hoặc nhiếm trùng, có $1 / 81 \mathrm{BN}$ sốt nhe điều trị ổn định ra viên được phân loai Clavien Dindo độ I (1,2\%). Tỷ lệ sốt sau TSNS ngược dòng của chúng tôi cũng tương đương với các nghiên cứu khác, khoảng từ $1,2-2,2 \%{ }^{7}$. Sốt có thể do nhiễm khuẩn trước mố, rối loạn chức năng bàng quang hoăc do áp lực nước trong thận cao khi mổ, tuy nhiên rất ít trường hợp dẫn tới sốc nhiễm trùng. Xét nghiệm tổng phẩn tích nước tiểu, cấy nước tiểu và điều trị nhiểm khuẩn tiết niệu trước mổ được thực hiện thường quy sẽ làm giảm các biến chứng trong và sau mổ.

Nghiên cứu của chúng tôi cho thấy tỉ lệ thành công có liên quan đến kích thước sỏi. Những trường hợp sỏi có kích thước chiều dọc dưới $10 \mathrm{~mm}$ có khả năng sạch sỏi trong mổ cao hơn và biến chứng trong mố ít hơn so với những trường hợp sỏi có chiêu dọc trên $10 \mathrm{~mm}$. Sự khác biệt này có ý nghĩa thống kê với $p=0,038(<0,05)$. Cheung và cộng sự đã TSNS ngược dòng sỏi NQ $1 / 3$ dưới bằng Holmium laser cho 69 bệnh nhân và ghi nhận không có sự khác biệt có ý nghĩa thống kê đối với tỷ lệ tán sỏi thành công ở nhóm sỏi có kích thước dưới $10 \mathrm{~mm}$ và trên $10 \mathrm{~mm}$ (tỷ lệ thành công lần lượt là $100 \%$ và $92 \%)^{8}$. Christian Seitz ghi nhân tỷ lê sach sỏi có sự khác biệt đối với sỏi có kích thước lớn hơn $20 \mathrm{~mm}$. Đối với sỏi gây cản trở lưu thông NQ có kích thước lớn hơn $16 \mathrm{~mm}$ tỷ lệ sạch sỏi khác biệt có ý nghĩa thống kê $(p<0,05)$.

Nghiên cứu của chúng tôi cho thây tỉ lệ thành công trong mổ có liên quan với tình trạng niệu quản.Tỷ lệ thành công ở nhóm có hẹp do viêm dính niệu quản tại vị trí ngay dưới sỏi là $100 \%$, trong đó có $4 / 6$ BN đạt kết quả tốt, chiếm $66,7 \%$. Sự khác biệt có ý nghĩa thống kê với $p=0,010$.

Kết quả nghiên cứu cho thấy tỷ lệ thành công của nhóm thận không ứ nước, ứ nước độ I, ứ nước độ II đều đạt $100 \%$, trong đó đạt kết quả tốt lần lượt là $100 \%, 93,2 \%$ và $90, \%$; tỷ lệ thành công của nhóm thận ứ nước độ III là 85,7\% trong đó có $50 \% \%$ đạt kết quả tốt. Sự khác biệt có ý nghĩa thống kê với $p=0,012<0,05$. Theo khuyến cáo của hội tiết niệu Mỹ (2007) thì chì định tán sỏi niệu quản nội soi không đề cập đến mức độ ứ nước và chức năng thận.

Nghiên cứu của chúng tôi ghi nhận các yếu tố như tuổi, giới tính, vị trí bên có sỏi, số lượng sỏi, độ cản quang không ảnh hưởng đến kết quả điều trị $(p>0,05)$

\section{KẾT LUẬN}

Phương pháp tán sỏi niêuu quản ngược dòng bằng Laser Holmium có tỷ lệ thành cổng $\mathrm{caO}$ $(98,8 \%)$, kết quả phụ thuộc chủ yếu vào kích thước sỏi,tình trạng niệu quản và mức độ ứ nước thận. Kỹ thuật tán sỏicó biến chứng ít và nhe, chủ yếu là đái máu và đau sau mổ ở mức đố nhẹ, thường tự hết sau 1-2 ngày. Các yếu tố như tuổi, giới tính, vị trí bên có sỏi, số lượng sỏi, độ cản quang không ảnh hưởng đến kết quả điều trị.

\section{TÀI LIẸU THAM KHẢO}

1. Elton TJ, Roth CS, Berquist TH, Silverstein MD. A clinical prediction rule for the diagnosis of ureteral stone in emergency departments. J Gen Intern Med. 1993;8:57-62.

2. Wolf JS., Jr Treatment selection and outcomes: ureter calculi. Urol Clin North Am. 2007;34:421-430.

3. Elhilali MM, Badaan S, Ibrahim A, Andonian S. Use of the moses technology to improve holmium laser lithotripsy outcomes: a preclinical study. J Endourol. 2017;31:598-604.

4. Türk C, Petř́́k A, Sarica $K$, et al. EAU guidelines on interventional treatment for urolithiasis. Eur Urol. 2016;69:475-82.

5. Geavlete 'P, Georgescu D, Niţă G, et al. Complications of 2735 retrograde semirigid ureteroscopy procedures: a single center experience. J Endourol. 2006;20:179-85.

6. Vũ Lê Chuyên, Vũ Văn $T y$, Nguyễn Minh Quang, Đố Anh Toàn. (2006). "Nội soi ngược dông tán sỏi bằng xung hơi sỏi niệu quản lưng: kết quả từ 49 trường hợp sỏi niệu quann đoạn lưng được tán sỏi nội soi ngược dòng tại khoa niệu 
bệnh viện Bình Dân". Tap chíY hoc Việt Nam. Tập 319, 2/2006. Tr 254-261.

7. Abeshouse B. S. và Tankin L. H. (2012), Retrocaval ureter: Report of a case and a review of the literature, The American Journal of Surgery,
84(4), 383-393.

8. Cheung MC, Lee F, Yip SKH, Tam PC (2001). Outpatient holmium laser lithitripsy using semirigid ureteroscope: is the treatment outcome affected by stone load? Eur Urol; 39: 702-708

\section{TÁC ĐộNG CỦA BẠO HÀNH TẠI NƠ'I LÀM VIÊCC ĐỐI VỚI HỌC VIÊN ĐIỀU DƯỡNG TẠI TRƯỜNG ĐẠI HỌC Y DƯỢC THÁI NGUYÊN}

\section{TÓM TẮT}

Đặt vấn đề: Bạo hành tại bệnh viện đang ngày càng phổ biến, trong đó điều dưỡng là nhóm thường bi bạo hành vì phải trực tiếp, thường xuyên tiếp xúc với người bệnh. Nghiên cứu này được tiến hành nhằm muc tiêu: mô tả các tác đông của bao hành y tế đối với điều dưỡng viên. Đối tượng và phương pháp nghiên cứu: Nghiên cứu mô tả cắt ngang được thực hiện từ tháng 3 đến tháng 5 năm 2021. Hai trằm linh mồt học viên của các khóa hơc chuẩn hóa chức danh nghề nghiệp tại khoa điều dưỡng, trường Đại học $Y$ Dược Thái Nguyên được chọn thuận tiên vào nghiên cứu. Bốn mươi học viên báo cáo là đã̃ từng bị bạo hành. Các đối tượng này được phát vấn thông qua bộ câu hỏi tự điền về tình trạng của họ sau khi bị tấn công. Kết quả: Đối tượng gặp bạo hành y tế đa số là nữ giới, tuổi từ 30 đến dưới 40 tuổi, chủ yếu ở các khoa nội trú, khoa cấp cứu và phòng khám. Sau khi bị tấn công, $90 \%$ điều dưỡng cảm thấy lo lắng về tình trạng bạo hành tại nơi làm việc. Cảm nhận của điều dưỡng sau khi bị bạo hành đó là thường xuyên nhớ lại lúc bị tấn công $(87,5 \%)$, lo sợ mình lại bị tấn công trong tương lai $(90 \%)$, cực kỳ cảnh giác, chuẩn bị phòng vệ trong lúc làm việc $(90 \%)$, có cảm giác không yêu nghể như xưa $(75 \%)$, và ho ước mình đã đước đào tạo về phòng tránh bạo hành tại nơi làm việc $(95 \%)$. Kết luâan: Hầu hết điều dưỡng viên sau khi trải qua bao hành y tế đều cảm thấy lo lắng và thường xuyên nhớ lại lúc bi tấn công. Điều này khiến cho họ cảm thấy lo sợ và luôn cảnh giác, làm họ giảm đi sự gắn kết và yêu nghề. Mong muốn của họ là được đào tạo về phòng tránh bạo hành tại nơi làm việc.

Tư khóa: Bạo hành nơi làm việc, Điều dưỡng.

\section{SUMMARY}

THE IMPACT OF WORKPLACE VIOLENCE ON NURSING STUDENTS AT THAI NGUYEN UNIVERSITY OF MEDICINE AND PHARMACY

Background: Workplace violence in hospitals is increasing every year, in which nurses are especially

\footnotetext{
${ }^{1}$ Viện Khoa học Sức khoẻ, Trường Đại học VinUni

${ }^{2}$ Trường $\oplus H$ Y Dược Thái Nguyên

Chịu trách nhiệm chính: Nguyễn Hoàng Long

Email: long.nh@vinuni.edu.vn

Ngày nhân bài: 5.8.2021

Ngày phản biện khoa học: 6.10 .2021

Ngày duyệt bài: 13.10.2021
}

\section{Nguyễn Hoàng Long ${ }^{1}$, Ngô Xuân Long ${ }^{2}$}

vulnerable to violence and other forms of aggression in the workplace. To clarify this issue, we conducted this study to describe the impact of workplace violence on nurses. Methods: A cross-sectional was carried out from March to May, 2021. 201 nursing students at Thai Nguyen University of Medicine and Pharmacy are conveniently selected, in which 40 of them who experienced workplace violence were asked by the self-administered questionnaire about their status after being attacked. Results: The majority of victims of workplace violence are women aged from 30 to under 40 years old, mainly in inpatient departments, emergency departments and medical examination department. After being attacked, $90 \%$ of the nurses felt anxious with an avarage score of $6.70 \pm 2.79$. Nurses' feelings after experiencing violence are often recalling the time of being attacked $(87.5 \%)$, afraid of being get attacked again in the future $(90 \%)$, are extremely wary and defend themself from violence at work $(90 \%)$, do not love their job as before $(75 \%)$, and wishing that they had been trained on preventing violence $(95 \%)$. Conclusions: Most of nursing students after experiencing workplace violence feel anxiety, and they often recall the time of being assaulted. They are wary and do not love their job as before. So they wish they had been trained in workplace violence prevention.

Keywords: Workplace violence, Nurse.

\section{I. ĐẶT VẤN ĐỀ}

Do tính chất công việc và thời gian tiếp xúc bệnh nhân nhiêuu, điều dưỡng viên là một trong những đối tượng có nguy cơ cao gặp phải các tình huống bạo hành tại nơi làm việc.-Nghiên cứu của Groenewold và cộng sự (2017) về tình trạng bạo hành ở nơi làm việc giai đoạn 2012-2015 tại Mỹ cho thấy, điều dưỡng viên là đối tượng có nguy cơ bị bạo hành y tế cao gấp 1,7 lần so với các nhóm nhân viên y tế khác [3]. Tổng quan 136 nghiên cứu quốc tế tại Anh, châu Á, châu Âu và khu vực Trung Đông của Spector và cộng sự (2014) cho thây, có 36,4\% điều dưỡng cho biết họ đã bị tấn công, với $67,2 \%$ trường hợp báo cáo về các vụ tấn công phi vật lý [5]. Nghiên cứu của Pinar và Ucmark (2011) về bạo hành lời nói và thể chất đối với điều dưỡng tại các khoa cấp cứu ở Istanbul Thổ Nhĩ Kỳ cũng chỉ ra rằng 